OPEN

SUBJECT AREAS:

NANOSCIENCE AND

TECHNOLOGY

CHEMISTRY

Received

5 August 2013

Accepted

23 October 2013

Published

14 November 2013

Correspondence and requests for materials should be addressed to

W.J.Z. (zhwj@nankai. edu.cn) or X.W.D. (xwdu@tju.edu.cn)

\section{Formation of Alumina Nanocapsules by High-Energy-Electron Irradiation of Na-dawsonite Nanorods}

\author{
Xiaochuan Duan' ${ }^{1}$ Tongil Kim', Lili Han², Jianmin $\mathrm{Ma}^{1}$, Xiwen $\mathrm{Du}^{2}$ \& Wenjun Zheng'
}

\begin{abstract}
'Department of Materials Chemistry, Key Laboratory of Advanced Energy Materials Chemistry (MOE), and TKL of Metal and Molecule-Based Material Chemistry, College of Chemistry, Synergetic Innovation Center of Chemical Science and Engineering (Tianjin), Nankai University, Tianjin, 300071 , People's Republic of China, ${ }^{2}$ School of Materials Science and Engineering, Tianjin University, Tianjin, 300072, People's Republic of China.
\end{abstract}

We report the synthesis of unique $\mathrm{Al}_{2} \mathrm{O}_{3}$ nanocapsules by high-energy-electron irradiation of Na-dawsonite and a formation mechanism different from thermal decomposition which usually produces $\mathrm{NaAlO}_{2}$. The novel decomposition process may open up a shortcut for fabricating hollow nanostructures.

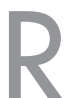
ecently, much attention has been paid to the engineering of nanostructures with electron-beam irradiation ${ }^{1,2}$. Electron-beam irradiation may cause two impacts: one is the interaction of electrons with atomic nucleus that leads to the displacement of atom by direct momentum transfer (denoted as knock-on displacement) and the other is the interaction with atomic electron that leads to atomic-electron excitation ${ }^{3}$. These characterized models of interaction of electron-beam irradiation can circumvent many difficulties, particularly, can induce the occurrence of special chemical reaction different from the conventional reaction conditions. This occurs because, whereas the chemical initiation requires a certain temperature for significant decomposition of initiator, the electron irradiation creates a stable flux of radicals independent of temperature. Moreover, bombardment with energetic electrons can cause chemical reactions locally or the sputtering of atoms from one part into another part and remove or mix the atoms in pre-defined areas ${ }^{1}$. Although electron-beam irradiation has been successfully applied on preparing carbon materials, less information is available regarding the irradiation effects on other inorganic materials ${ }^{4-14}$. In this regard, systematic studies are still lacking for developing electron-beam irradiation into a powerful technology for the synthesis of inorganic nanomaterials with desirable phases and shapes.

Interestingly, the resulting products in the most cases of electron-beam irradiation present hollow structures due to beam heating and related etching effect. Williams and co-workers have reported the evolution of Fe oxide and Fe hollow nanospheres from amorphous solid particles during exposure to the beam of the TEM ${ }^{15}$. Yang and co-workers systematically investigated the stability of $\mathrm{ZnO} / \mathrm{Al}_{2} \mathrm{O}_{3}$ core/shell nanowires under electron-beam irradiation and successfully obtained $\mathrm{Al}_{2} \mathrm{O}_{3}$ nanotubes via local etching of $\mathrm{ZnO}$ core by electron-beam ${ }^{16}$. Similarly, hollow $\mathrm{NaYF}_{4}: \mathrm{Yb}, \mathrm{Er}$ nanostructures ${ }^{17}$ and Se@C, Au/Se@C and $\mathrm{Ag}_{2} \mathrm{Se} @ \mathrm{C}$ core-shell spheres ${ }^{18}$ have been successfully fabricated through evaporation under electron-beam irradiation. Compared the traditional approaches to prepare hollow inorganic nanomaterials, including templating strategies and many other novel schemes, such as Ostwald ripening, Kirkendall effect, galvanic replacement, chemical etching and self-templating, it is reasonable to believe that electron-beam irradiation may present a more fast and efficient way for fabricating hollow nanostructures ${ }^{19-21}$.

In this communication, we investigate the decomposition of Na-dawsonite induced by electron-beam irradiation. We show that electron irradiation can transform Na-dawsonite nanorods into alumina nanocapsules, while thermal decomposition of the same starting material produces sodium aluminate $\left(\mathrm{NaAlO}_{2}\right)$. We demonstrate that the unusual alumina nanocapsules originate from the knock-on displacement and beam heating effects of the highenergy electrons. Given the effectiveness of the electron irradiation on controlling phases and morphologies of the products, we believe this technique may open up a new avenue for the production of special nanostructures ${ }^{22-27}$.

\section{Results}

To obtain monodisperse Na-dawsonite nanorods, we adopted an ionic liquid-assisted hydrothermal route using 1-butyl-2, 3-dimethylimidazolium chloride $([\mathrm{Bdmim}] \mathrm{Cl})$ as the template (details can be seen in Supporting 


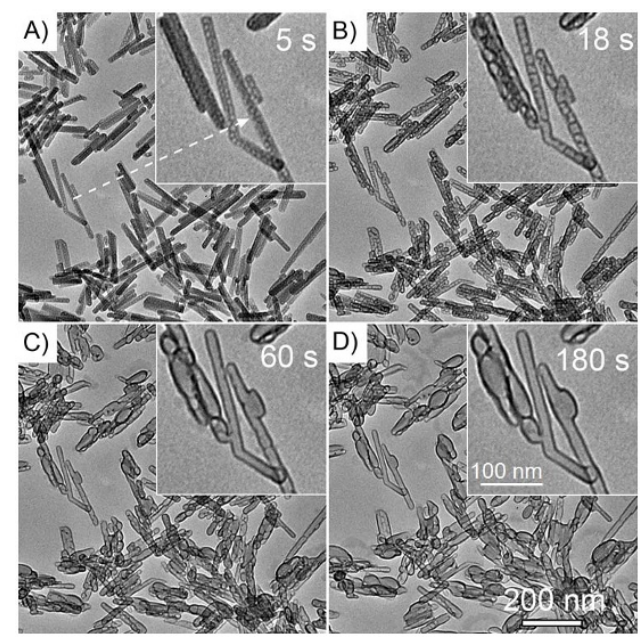

Figure 1 | TEM images of Na-dawsonite nanorods at (A) 5, (B) 18, (C) 60, and (D) $180 \mathrm{~s}$ exposure under $120 \mathrm{kV}$-electron-beam irradiation. The insets are enlarged TEM image of the area pointed by the arrow in (A).

Information, Scheme S1). The phase and purity of the as-prepared $\mathrm{Na}$-dawsonite were characterized by X-ray diffraction (XRD) and Fourier transformed infrared (FTIR) measurements. As shown in Figure S1, it is evident that all the diffraction peaks in Figure S1A can be precisely indexed to the orthorhombic structure of $\mathrm{NaAl}(\mathrm{OH})_{2} \mathrm{CO}_{3}$ with lattice constants $a=5.583 \AA$, $b=6.674 \AA$, $c$ $=10.425 \AA$ (JCPDS Card 45-1359). Both XRD and FTIR analysis confirm that the as-prepared products are pure in phase constitution. Figure S2A shows a typical SEM image of the products, indicating that the presence of homogeneous and well-shaped nanorods. According to SEM image shown in Figure S2B, Na-Dw nanorods possess a diameter of $20 \mathrm{~nm}$ and lengths in the range of $200 \sim$ $300 \mathrm{~nm}$.

After exposed to an electron beam accelerated by $120 \mathrm{kV}$, the NaDw nanorods gradually evolved into nanocapsules. Figure 1 shows four typical images reflecting the on-going evolution over $180 \mathrm{~s}$. It was found that voids first appeared at the internal of the nanorods after a rather short time, $5 \mathrm{~s}$ (Figure 1A). These voids gradually evolved into peapod-liked structures after $18 \mathrm{~s}$ iradiation (Figure 1B), and finally into hollow capsules after 60 and $180 \mathrm{~s}$ (Figures $1 \mathrm{C}$ and 1D). As the irradiation experiment was performed under higher energy $(200 \mathrm{kV})$ electron beam, the evolution from nanorods to nanocapsules can also be observed. Nevertheless, the transformation process took less time (30 s, see Figure S3).

Before electron beam irradiation, the sodium, aluminum and oxygen elements can be found in the samples with an atom ratio of $0.9: 1: 5.1$ (Na:Al:O) according to the energy-dispersive X-ray spectrum (EDS) (Figure 2A), which is very close to the stoichiometric ratio of $\mathrm{NaAl}(\mathrm{OH})_{2} \mathrm{CO}_{3}$. However, the EDS of the nanocapsules after $180 \mathrm{~s}$ irradiation indicates that only aluminum and oxygen elements were left with an atomic ratio of $1: 1.6(\mathrm{Al}: \mathrm{O})$, being very close to the stoichiometric ratio of $\mathrm{Al}_{2} \mathrm{O}_{3}$ (Figure 2B). Elemental mapping (Figure 2C) results showed that the nanocapsules contain $\mathrm{Al}$ and $\mathrm{O}$ elements without $\mathrm{Na}$ element, which is consistent with the EDS analysis. Figures 2E and 2F show high resolution TEM (HRTEM) image and its corresponding fast Fourier transform (FFT) pattern, respectively, the interplanar distance is calculated as $0.201 \mathrm{~nm}$, corresponding to the (400) crystal planes of cubic $\gamma-\mathrm{Al}_{2} \mathrm{O}_{3}$. Based on the above results, we can conclude that the nanocapsules are composed of alumina.
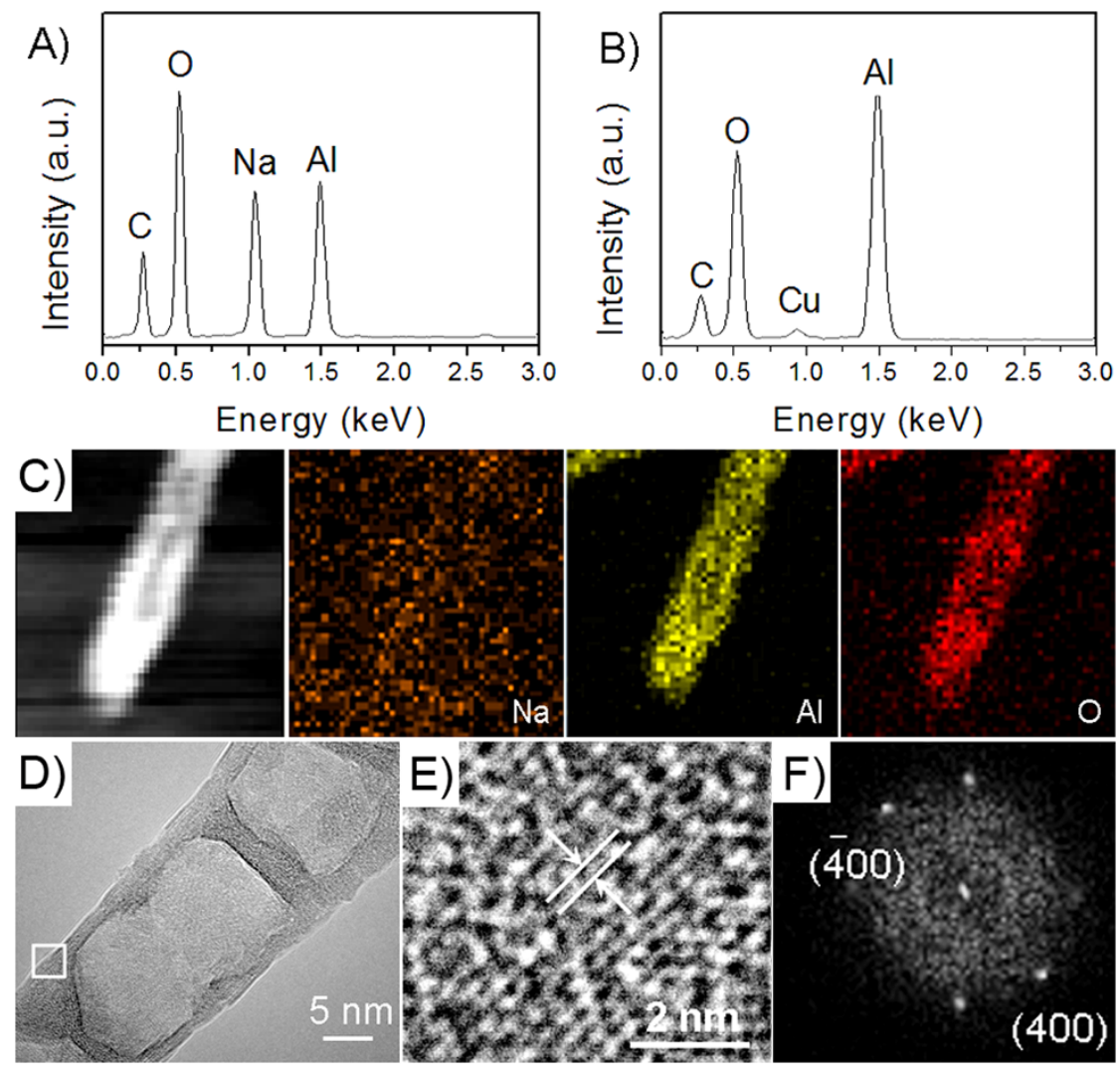

Figure 2 Compositional and structural characterizations of the nanocapsules. (A) EDS spectrum of Na-dawsonite nanorods, (B) EDS spectrum of the product after electron-beam irradiation, (C) high-angle-annular-dark-field scanning transmission electron microscopy (HAADF-STEM) image of a nanocapsule and corresponding elemental mappings of $\mathrm{Na}, \mathrm{Al}$, and $\mathrm{O}$, (D) TEM image of a nanocapsule formed by $200 \mathrm{kV}$-electron-beam irradiation, (E) HRTEM image of the area in the frame in D, (F) FFT pattern of HRTEM image in E. 

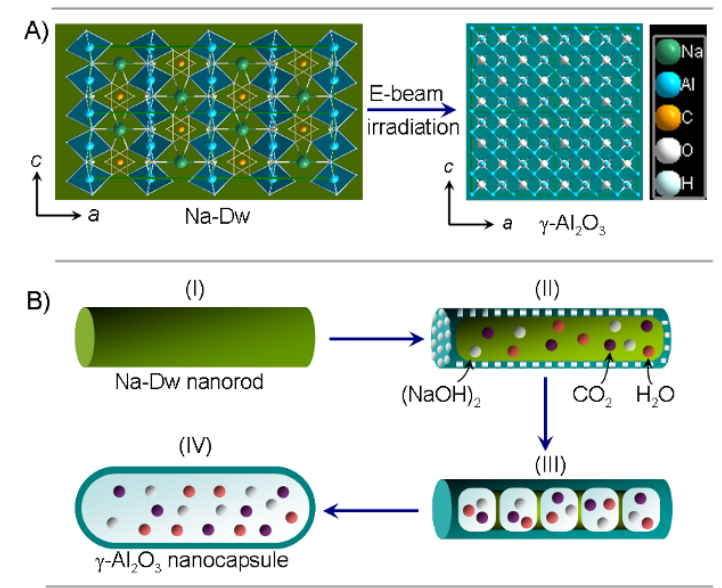

Figure 3 Schematic illustration of the structural and morphological change from $\mathrm{Na}$-dawsonite nanorod to alumina nanocapsule under electron-beam irradiation. (A) Structural change $(2 \times 2$ cells $)$, (B) morphological evolution.

In contrast, when the $\mathrm{Na}$-dawsonite nanorods were heated in air or vacuum, sodium aluminate $\left(\mathrm{NaAlO}_{2}\right)$ was obtained according to the TGA and XRD analysis (Figures S4 and S5 in supporting information). From the TGA curve, it can be seen that the decomposition of Na-Dawsonite appears to occur by three steps with in a total weight loss of approximately $41.1 \%$ up to $720^{\circ} \mathrm{C}$, which is close to the theoretical value $(43.1 \%)$. These results are consistent with those previously reported for the thermal decomposition of Na-dawsonite ${ }^{28}$, which can be formulated as:

$$
\mathrm{NaAl}(\mathrm{OH})_{2} \mathrm{CO}_{3} \rightarrow \mathrm{NaAlO}_{2}+\mathrm{CO}_{2}+\mathrm{H}_{2} \mathrm{O}
$$

\section{Discussion}

Above results indicates that the high-energy-electron irradiation of $\mathrm{Na}$-dawsonite leads to a different product from thermal decomposition, thus we infer that the transformation of $\mathrm{Na}$-dawsonite under electron beam follows a novel mechanism.

Structurally, Na-dawsonite consists of an assemblage of edgesharing distorted $\mathrm{AlO}_{2}(\mathrm{OH})_{4}$ and $\mathrm{NaO}_{4}(\mathrm{OH})_{2}$ octahedra and $\mathrm{CO}_{3}{ }^{2-}$ groups, represented in Figure $3 \mathrm{~A}^{29,30}$. Several possible mechanisms are responsible for the decomposition of Na-dawsonite under electron irradiation, such as beam heating, knock-on displacement, and ionization of valence electrons. The highest temperature rise due to the beam heating was calculated to be $889 \mathrm{~K}$ (details can be seen in Supplementary Information), which is in the temperature range for producing $\mathrm{NaAlO}_{2}$ (Figure S5). Hence, the beam heating can break the weak hydrogen bonds associated with $\mathrm{CO}_{3}$ groups and give off $\mathrm{CO}_{2}$ and $\mathrm{H}_{2} \mathrm{O}$ molecules. Nevertheless, the beam heating itself cannot generate $\mathrm{Al}_{2} \mathrm{O}_{3}$. The elimination of $\mathrm{Na}$ atoms should be ascribed to knock-on displacement, since the high energy (both 120 and $200 \mathrm{kV}$ ) incident electrons have enough energy to displace $\mathrm{Na}$ atoms due to the lower bond dissociation energies of $\mathrm{Na}-\mathrm{O}(257 \mathrm{~kJ} / \mathrm{mol})$ and $\mathrm{Na}-\mathrm{H}$ bonds $(201 \mathrm{~kJ} / \mathrm{mol}$ ) (see Table S1). Subsequently, the active $\mathrm{Na}$ atoms react with $\mathrm{H}_{2} \mathrm{O}$ to form $(\mathrm{NaOH})_{2}$ vapor which easily comes out of the system ${ }^{31,32}$, resulting in the formation of $\mathrm{Al}_{2} \mathrm{O}_{3}$. Since the displacement mechanism is directly dependent on the beam energy, it is not surprising that a higher energy $(200 \mathrm{kV})$ beam leads to an increased decomposition rate (Figure S3), while lower energy $(10 \mathrm{kV})$ beam can not cause decomposition of $\mathrm{Na}$ dawsonite at all (Figure S6). According to the above analysis, the novel decomposition induced by electron-beam irradiation can be formulated as:

$$
2 \mathrm{NaAl}(\mathrm{OH})_{2} \mathrm{CO}_{3} \rightarrow \mathrm{Al}_{2} \mathrm{O}_{3}+2 \mathrm{NaOH}+2 \mathrm{CO}_{2}+\mathrm{H}_{2} \mathrm{O}
$$

The morphology of the product changes with the above phase transformation. Na-dawsonite nanorods become porous from surface due to the escape of $(\mathrm{NaOH})_{2}, \mathrm{H}_{2} \mathrm{O}$ and $\mathrm{CO}_{2}$ vapors in the initial stage of decomposition (Figure $1 \mathrm{~A}$ and Figure 3BII). The produced $\mathrm{Al}_{2} \mathrm{O}_{3}$ can crystallize and connect into a compact surface layer because the temperature $(889 \mathrm{~K})$ generated by beam heating is higher than the critical crystallization temperature of alumina $(873 \mathrm{~K})^{33,34}$, As a result, a bean-pod-like shell forms, and the vapors generated by subsequent decomposition of residual $\mathrm{Na}$ dawsonite are sealed in its cavities (Figure 3BIII). The pressure in the cavities increases dramatically with the production of many vapors during the further decomposition, and the expansion of nanorods gives the hollow capsule-like structure (Figure 3BIV).

In summary, we studied the decomposition of $\mathrm{Na}$-dawsonite under electron-beam irradiation and proposed a novel mechanism different from the thermal decomposition, in which $\mathrm{Na}$ atoms were eliminated owing to the knock-on displacement of incident electrons, and residual Al-O framework was dilated by the decomposed vapor and crystallized into alumina nanocapsules by beam heating. Such a decomposition behavior under electron-beam irradiation process is highly interesting, as it provides an insight on the interaction of electron beam with materials, and could serve as a novel approach for the synthesis of hollow or tubular nanostructures.

\section{Methods}

Materials. 1-butyl-2, 3-dimethylimidazolium chloride ([Bdmim $] \mathrm{Cl})$ was obtained from Lanzhou Greenchem ILS, LICP. CAS. China. Other chemicals were purchased and used without further purification. The water used was deionized.

Synthesis of Na-dawsonite nanorods. In a typical synthesis procedure, $2.0 \mathrm{mmol}$ of $\mathrm{AlCl}_{3} \cdot 6 \mathrm{H}_{2} \mathrm{O}$ and $2 \mathrm{mmol}$ of [ $\left.\mathrm{Bdmim}\right] \mathrm{Cl}$ was put into $5 \mathrm{~mL}$ of deionized water under stirring to form a homogenous solution. Subsequently, $10 \mathrm{~mL}$ of $\mathrm{NaHCO}_{3}$ aqueous solution $(1 \mathrm{M})$ was added dropwise into the above homogenous solution under continuous stirring. After stirring for $10 \mathrm{~min}$, the total solution was transferred into a stainless-steel autoclave with a capacity of $20 \mathrm{~mL}$, sealed and heated at $120^{\circ} \mathrm{C}$ for $12 \mathrm{~h}$. When the reaction was completed, the autoclave was cooled to room temperature naturally. The resultant product was collected and washed with deionized water, and anhydrous ethanol for several times until the solution was neutral. The final product was dried in a vacuum at $80^{\circ} \mathrm{C}$ for $3 \mathrm{~h}$.

Electron-beam-irradiation-induced formation of alumina nanocapsules. The asprepared samples were first dispersed in ethanol as a suspension. Then, the resulting dispersion were dropped onto the copper grids covered with holey carbon support films. Finally, a sample on a grid was introduced into a transmission electron microscope vacuum chamber to examine its nanostructure and phase structure. Besides, structure evolution was observed in-situ under electron irradiation.

Characterization. The products were characterized by XRD, SEM, TEM, HR-TEM, and FT-IR measurements. XRD measurements were performed in a Rigaku D/max 2500 diffractometer with $\mathrm{Cu} \mathrm{K} \alpha$ radiation $(\lambda=0.154056 \mathrm{~nm})$ at $\mathrm{V}=40 \mathrm{kV}$ and $\mathrm{I}=$ $150 \mathrm{~mA}$, and the scanning speed was $8 \% \mathrm{~min}$. Morphology observations were performed on a JEOLJSM-6700F field emission scanning electron microscope (FESEM). TEM and corresponding HR-TEM images were recorded with a Tecnai G2 20S-Twin transmission electron microscope operating at accelerating voltages of 120 and $200 \mathrm{kV}$. The composition was analyzed with an Oxford INCA energy-dispersive spectroscopy (EDS) module attached to the TEM microscope. The FT-IR spectra of the samples were conducted at room temperature with a KBr pellet on a VECTOR-22 (Bruker) spectrometer ranging from 400 to $4000 \mathrm{~cm}^{-1}$. TGA experiments (Du Pont Instruments 951 thermogravimetric analyzer) were performed on a $100 \mathrm{mg}$ of sample from room temperature to $700^{\circ} \mathrm{C}$ in flowing nitrogen gas at a heating rate of $5^{\circ} \mathrm{C} / \mathrm{min}$. The thermal conductivity of the sample was measured at $300 \mathrm{~K}$ with a thermal conductivity instrument (TC3000) made by the Xian Xiaxi company in China. The thermal conductivity of the sample was the average of three time measurements.

1. Krasheninnikov, A. V. \& Banhart, F. Engineering of nanostructured carbon materials with electron or ion beams. Nature Mater. 6, 723-733 (2007)

2. Zheng, H. M., Mirsaidov, U. M., Wang, L. W. \& Matsudaira, P. Electron beam manipulation of nanoparticles. Nano Lett. 12, 5644-5648 (2012).

3. Du, X. W., Takeguchi, M., Tanaka, M. \& Furuya, K. Formation of crystalline Si nanodots in $\mathrm{SiO}_{2}$ films by electron irradiation. Appl. Phys. Lett. 82, 1108-1110 (2003). 
4. Li, J. \& Banhart, F. The engineering of hot carbon nanotubes with a focused electron beam. Nano Lett. 4, 1143-1146 (2004).

5. Sun, L. et al. Carbon nanotubes as high-pressure cylinders and nanoextruders. Science 312, 1199-1202 (2006).

6. Liu, J. W. et al. A family of carbon-based nanocomposite tubular structures created by in situ electron beam irradiation. ACS Nano 6, 4500-4507 (2012).

7. Susi, T. et al. Atomistic description of electron beam damage in nitrogen-doped graphene and single-walled carbon nanotubes. ACS Nano 6, 8837-8846 (2012).

8. Xu, S. et al. Nanometer-scale modification and welding of silicon and metallic nanowires with a high-intensity electron beam. Small 1, 1221-1229 (2005).

9. Simonsen, S. B. et al. Direct observations of oxygen-induced platinum nanoparticle ripening studied by in situ TEM. J. Am. Chem. Soc. 132, 7968-7975 (2010)

10. Wei, X., Wang, M. S., Bando, Y. \& Golberg, D. Electron-beam-induced substitutional carbon doping of boron nitride nanosheets, nanoribbons, and nanotubes. ACS Nano 5, 2916-2922 (2011).

11. Zhai, Y. et al. Superparamagnetic plasmonic nanohybrids: shape-controlled synthesis, TEM-induced structure evolution, and efficient sunlight-driven inactivation of bacteria. ACS Nano 5, 8562-8570 (2011).

12. Hong, Y. K. et al. Fine characteristics tailoring of organic and inorganic nanowires using focused electron-beam irradiation. Angew. Chem. Int. Ed. 50, 3734-3738 (2011).

13. Dai, S. et al. Electron-beam-induced elastic-plastic transition in Si nanowires. Nano Lett. 12, 2379-2385 (2012).

14. Lou, X. W. et al. Encapsulation and Ostwald ripening of $\mathrm{Au}$ and $\mathrm{Au}-\mathrm{Cl}$ complex nanostructures in silica shells. Adv. Funct. Mater. 16, 1679-1684 (2006).

15. Latham, A. H., Wilson, M. J., Schiffer, P. \& Williams, M. E. TEM-induced structural evolution in amorphous Fe oxide nanoparticles. J. Am. Chem. Soc. 128, 12632-12633 (2006).

16. Yang, Y.et al. Transmission electron microscopy in situ fabrication of $\mathrm{ZnO} / \mathrm{Al}_{2} \mathrm{O}_{3}$ composite nanotubes by electron-beam-irradiation-induced local etching of $\mathrm{ZnO} / \mathrm{Al}_{2} \mathrm{O}_{3}$ core/shell nanowires. Small 4, 2112-2117 (2008).

17. Feng, W., Sun, L. D., Zhang, Y. W. \& Yan, C. H. Solid-to-hollow single-particle manipulation of a self-assembled luminescent $\mathrm{NaYF}_{4}: \mathrm{Yb}$, Er nanocrysta monolayer by electron-beam lithography. Small 5, 2057-2060 (2009).

18. Zhu, J.et al. Fabrication of core-shell structure of $\mathrm{M} @ \mathrm{C}\left(\mathrm{M}=\mathrm{Se}, \mathrm{Au}, \mathrm{Ag}_{2} \mathrm{Se}\right)$ and transformation to yolk - shell structure by electron beam irradiation or vacuum annealing. Chem. Mater. 21, 3848-3852 (2009).

19. Zheng, R. et al. $\mathrm{Na}_{2} \mathrm{SO}_{4}$ monocrystal nanowires - aspect ratio control and electron beam radiolysis. Inorg. Chem. 49, 6748-6754 (2010).

20. Wang, Z., Zhou, L. \& Lou, X. W. Metal oxide hollow structures for lithium-ion batteries. Adv. Mater. 24, 1903-1911 (2012).

21. Zeng, H. C. Synthesis and self-assembly of complex hollow materials. J. Mater. Chem. 21, 7511-7526 (2010).

22. Piao, Y.et al. Wrap-bake-peel process for nanostructural transformation from $\beta$ $\mathrm{FeOOH}$ nanorods to biocompatible iron oxide nanocapsules. Nature Mater. 7, 242-247 (2008).

23. Lou, X. W., Archer, L. A. \& Yang, Z. Hollow micro-/nanostructures: synthesis and applications. Adv. Mater. 20, 3987-4019 (2008)

24. Liu, J., Xia, H., Xue, D. \& Lu, L. Double-shelled nanocapsules of $\mathrm{V}_{2} \mathrm{O}_{5}$-based composites as high-performance anode and cathode materials for $\mathrm{Li}$ ion batteries. J. Am. Chem. Soc. 131, 12086-12087 (2009).
25. Li, W., Yoon, J. A. \& Matyjaszewski, K. Dual-reactive surfactant used for synthesis of functional nanocapsules in miniemulsion. J. Am. Chem. Soc. 132, 7823-7825 (2010).

26. Wang, Z. et al. Engineering nonspherical hollow structures with complex interiors by template-engaged redox etching. J. Am. Chem. Soc. 132, 16271-16277 (2010).

27. Mallavajula, R. K. \& Archer, L. A. Nanocrystal self-assembly assisted by oriented attachment. Angew. Chem. Int. Ed. 50, 578-580 (2011).

28. Stoica, G., Abelló, S. \& Pérez-Ramírez, J. Na-dawsonite derived aluminates for DMC production by transesterification of ethylene carbonate. Appl. Catal. A-Gen. 365, 252-260 (2009)

29. Stoica, G. \& Pérez-Ramírez, J. Reforming dawsonite by memory effect of AACH derived aluminas. Chem. Mater. 19, 4783-4790 (2007)

30. Stoica, G., Groen, J. C., Abelló, S., Manchanda, R. \& Pérez-Ramírez. Reconstruction of dawsonite by alumina carbonation in $\left(\mathrm{NH}_{4}\right)_{2} \mathrm{CO}_{3}$ : requisites and mechanism. J. Chem. Mater. 20, 3973-3982 (2008).

31. Liu, Y. \& Ren, D. Inorganic Chemistry Books Compendium Publisher: Zhang, Q. Beijing, 1, 422-427 (1993).

32. Džidić, I. \& Kebarle, P. Hydration of the alkali ions in the gas phase. J. Phy. Chem. 74, 1466-1474 (1970).

33. Morris, S. M., Fulvio, P. F. \& Jaroniec, M. Ordered mesoporous aluminasupported metal oxides. J. Am. Chem. Soc. 130, 15210-15216 (2008).

34. Cai, W., Yu, J., Anand, C., Vinu, A. \& Jaroniec, M. Facile synthesis of ordered mesoporous alumina and alumina-supported metal oxides with tailored adsorption and framework properties. Chem. Mater. 23, 1147-1157 (2011).

\section{Acknowledgments}

This work was supported by the National Natural of Science Foundation of China (Grant No. 21073095, 21371101, 51171127, and 51102176) and 111 project (B12015).

\section{Author contributions}

X.C.D. and T.K. designed and performed the experiments. L.H. and J.M. carried out the materials characterization and analysis. W.Z. and X.W.D. conceived and supervised the overall project. X.C.D., W.Z. and X.W.D. wrote the manuscript with inputs from all authors

\section{Additional information}

Supplementary information accompanies this paper at http://www.nature.com/ scientificreports

Competing financial interests: The authors declare no competing financial interests.

How to cite this article: Duan, X.C. et al. Formation of Alumina Nanocapsules by High-Energy-Electron Irradiation of Na-dawsonite Nanorods. Sci. Rep. 3, 3218; DOI:10.1038/srep03218 (2013)

\footnotetext{
cc)(1) (2) This work is licensed under a Creative Commons Attribution-

BY NC SA NonCommercial-ShareAlike 3.0 Unported license. To view a copy of this license, visit http://creativecommons.org/licenses/by-nc-sa/3.0
} 